- Amalgam continues to predominate as the restorative material of choice for the restoration of permanent teeth.

- Glass-ionomer cements are widely used as luting cements and as bases and restorations by younger practitioners.

- Rubber dam is not used routinely.

- Stainless steel crowns are placed by a minority of practitioners for the restoration of deciduous molars.

\title{
Contemporary dental practice in the UK: aspects of direct restorations, endodontics and bleaching
}

\author{
N. H. F. Wilson, ${ }^{1}$ G. J. Christensen, ${ }^{2}$ S. W. Cheung, ${ }^{3}$ F. J. T. Burke ${ }^{4}$ and P. A. Brunton ${ }^{5}$
}

\begin{abstract}
Objectives To investigate by questionnaire, the use and selection of materials and techniques for the placement of direct restorations and the provision of endodontics and bleaching by dental practitioners in the North West of England and Scotland.

Methods A questionnaire was sent to 1,000 general dental practitioners selected at random from dentists in Scotland and the North West of England. Non-responders were sent another questionnaire after a period of 4 weeks had elapsed.

Results A total of 701 usable questionnaires were returned, giving a response rate of 70\%. The most commonly used material for the restoration of Class $\mathrm{II}$ cavities in premolar and permanent molar teeth was amalgam $(n=605,86 \%)$ and $(n=634,90 \%)$ respectively. Many practitioners ( $n=419,60 \%)$ felt amalgam should continue to be used but a majority $(n=374,66 \%)$ remained unconvinced about the merits of amalgam bonding. A minority $(n=63,9 \%)$ of practitioners used predominantly directly placed resin composite rather than amalgam to restore Class II cavities in premolar and permanent molar teeth. Homebased vital bleaching was provided by a significant number $(n=245$, $35 \%)$ of practitioners with only $18 \%(n=123)$ providing practice-based bleaching. The most commonly used endodontic obturation technique was cold lateral condensation $(n=527,75 \%)$ with $61 \%(n=425)$ of respondents not using rubber dam routinely for endodontics.

Conclusions For the practitioners in this survey, amalgam was the most frequently selected direct restorative material. Few practitioners used amalgam bonding let alone direct resin composite for posterior restorations. Home-based rather than practice-based bleaching procedures were preferred, as were more traditional endodontic obturation techniques.
\end{abstract}

1Professor of Restorative Dentistry, Guy's, King's and St. Thomas' Dental Institute, King's College London, Guy's Campus, London SE1 9RT, UK; ${ }^{2}$ Director, Clinical Research Associates, 3707 N. Canyon Road \#6, Provo, Utah 84604, USA; ${ }^{3}$ Statistician, Oxford, UK; ${ }^{4}$ Professor of Primary Dental Care, University of Birmingham School of Dentistry, St.Chad's Queensway, Birmingham B4 6NN, UK; ${ }^{5}$ Professor of Restorative Dentistry, Leeds Dental Institute, University of Leeds, Clarendon Way, Leeds, West Yorkshire LS2 9LU Correspondence to: Prof P. A. Brunton, Professor of Restorative Dentistry, Leeds Dental Institute, University of Leeds, Clarendon Way, Leeds, West Yorkshire LS2 9LU E-mail:paul.brunton@man.ac.uk

\section{Refereed Paper}

Received 23.05.03; Accepted 20.01.04

doi:10.1038/sj.bdj.4811905

๑ British Dental Journal 2004; 197: 753-756

\section{INTRODUCTION}

This is one of three papers reporting the findings of a survey designed to provide a profile of everyday aspects of contemporary general dental practice in the UK. The first of these three papers reported on demographic data and practising arrangements, and the third paper will report the findings of the survey pertaining to indirect restorations. ${ }^{2}$ The present paper deals primarily with aspects of direct restorations - the placement and replacement of such restorations comprising a very large element of everyday general dental practice. ${ }^{3}$ Estimates of annual expenditures for 'replacement dentistry' alone ${ }^{4}$ make the provision of direct restorations in dentistry a worldwide billion-dollar industry. ${ }^{3}$ In the UK, the placement and replacement of direct restorations in both the public and private sector is considered to remain practitioners' most common form of clinical intervention. The number of direct restorations placed annually in England and Wales has however, recently (2000-2002) declined. ${ }^{5}$

\section{MATERIALS AND METHODS}

Arrangements for the survey and for the handling and analysis of the data obtained are described in detail in another of the three papers reporting the present study. ${ }^{1}$ In summary, the questionnaire was based, in part, on the questionnaire used in the annual Clinical Research Associates (CRA) survey of dentists in the USA. The questionnaire comprised 18 sections including a total of 79 questions. The questionnaire, once piloted, was sent to a random sample of 1,000 general dental practitioners in the North West of England $(n=500)$ and Scotland $(n=500)$. A second questionnaire was sent to non-respondents after 4 weeks. The data obtained was computerised and analysed using SPSS for Windows version 10 (SPSS Inc., Chicago, IL, USA). Summary statistics including cross-tabulations were obtained and, where appropriate, nonparametric tests, including Mann Whitney and Kruskal Wallis were performed. The level of significance was set at $1 \%$ because of the number of tests being carried out, and to reduce the chance of getting false positive results.

In designing the questionnaire, a major concern was the number of questions, which could reasonably be included - the longer and more detailed the questionnaire, the less likely busy practitioners would be to complete and return it. As a consequence, the 


\section{RESEARCH}

number of questions in relation to specific aspects of everyday clinical practice, including direct restorations, had to be strictly limited and carefully constructed.

\section{RESULTS}

A total of 701 usable, completed questionnaires were returned, with 345 from the North West of England and 356 from Scotland, giving a response rate of 70\%. Details of the respondents, including practice location, position within the practice, NHS activity, practice workload, dental team arrangements, and participation in postgraduate education have been reported. ${ }^{1}$

\section{Restorative materials - posterior teeth}

When questioned as to the most commonly used material for the direct restoration of Class II cavities in premolar and permanent molar teeth, the respondents indicated that dental amalgam continues to predominate - premolars ( $n=605,86 \%$ of respondents), permanent molars ( $n=634,90 \%$ of respondents). Regarding the use of resin-based composites as the most commonly used direct restorative material for the restoration of Class II cavities, this was limited to $9 \%(n=63)$ of the respondents in relation to premolars and 5\% $(n=35)$ of the respondents for permanent molar teeth.

Interestingly, when the respondents went on to comment on their attitude towards the use of dental amalgam, only 60\% ( $n=419)$ agreed that amalgam should continue to be used, with a further 30\% $(n=209)$ of the respondents being undecided on this issue.

Of those who did not use amalgam bonding, 66\% $(n=374)$ were not convinced as to the need for this procedure, with a small but significant minority of respondents indicating that amalgam bonding was too time-consuming $(n=98,17 \%)$ and/or too expensive $(n=87,15 \%)$. Nearly $23 \%(n=131)$ of the respondents would appear to have found the question on amalgam bonding irrelevant as they simply ticked the option 'not covered by third party payment'.

The findings as to the factors influencing the final decision as to what material should be used to restore a Class II cavity were also of interest - more than one factor could be selected: durability, $56 \%(n=394)$; patient preference, 50\% $(n=351)$; need to withstand occlusal loading, 45\% $(n=316)$; aesthetics, 34\% $(n=235)$; concern about mercury toxicity, 9\% $(n=62)$.

\section{Glass-ionomer cements}

Glass-ionomer cements (GICs) were found to be most favoured for the luting of indirect restorations ( $n=477,68 \%$ of respondents). Only $66 \%(n=461)$ of the respondents found applications for GICs and related materials as restorative materials in permanent teeth. Regarding the use of GICs as liners and/or bases, this was limited to $47 \%(n=331)$ of the respondents. There was a strong association between the two regions and the use of GIC for restorations $(P<0.01$; Fisher's Exact test $P=0.004)$.

In the North West of England 29\% of respondents did not use GICs for restorations compared with 39\% in Scotland.

Younger practitioners, in terms of years since graduation, were more likely to use GICs for bases than older practitioners $(P<0.01$; Mann Whitney $U, P=0.001$ ). Similarly there was a significant difference between younger and older practitioners in respect of the use of GICs for restorations $(P<0.01$; Mann Whitney $\mathrm{U}, P=0.007)$, with the younger practitioners being more likely to apply GICs for such purposes.

\section{Bleaching}

Thirty five percent $(n=245)$ of the respondents indicated that they provided home-based vital bleaching and 18\% $(n=123)$ indicated that they provide practice-based bleaching. The findings in relation to experience of side effects with bleaching are set out in Table 1 .
Table 1 Details of side effects experienced by respondents who provided bleaching

\begin{tabular}{|c|c|c|}
\hline & $\begin{array}{c}\text { Home-based } \\
\text { bleaching } \\
\text { No. }(\%)\end{array}$ & $\begin{array}{c}\text { Practice-based } \\
\text { bleaching } \\
\text { No. }(\%)\end{array}$ \\
\hline Soft tissue inflammation & $54(22)$ & $26(21)$ \\
\hline Tooth sensitivity & $176(72)$ & 41 (33) \\
\hline Systemic effects & $1 \quad(0)$ & - \\
\hline Others & $6 \quad(2)$ & $5 \quad(4)$ \\
\hline
\end{tabular}

\section{Endodontics}

The two questions asked in relation to endodontics revealed that only 75\% $(n=527)$ of the respondents considered root canal therapy to be safe, with $15 \%(n=104)$ of the respondents indicating that they were beginning to question the acceptability of standard root canal procedures. Cold lateral condensation techniques predominated ( $n=527,75 \%$ of respondents). Younger practitioners tended to use cold lateral condensation of gutta percha compared with older graduates who favoured warm lateral condensation of gutta percha. This difference was highly significant $(P<0.001$, Kruskall Wallis one-way ANOVA, $P=0.001$ ).

\section{Rubber dam}

Sixty-one per cent ( $n=425$ ) of respondents indicated that they did not use rubber dam for endodontics, let alone any other procedure.

There was a difference between the practitioners in Scotland and the North West of England with respect to the procedures for which rubber dam was used routinely. The difference was statistically significant $(\mathrm{P}<0.01$; Pearson chi-square value $=11.25,3$ degrees of freedom, $\mathrm{P}=0.01$ ). In the North West of England $83 \%$ of the respondents did not use rubber dam for endodontics, with $3 \%$ having used it for practice-based bleaching and 1\% for operative dentistry. Of the respondents in Scotland, 65\% did not use rubber dam for endodontics, with 3\% having used it for practice-based bleaching and $4 \%$ for operative dentistry.

\section{Paediatric dentistry}

Two questions in relation to restorative aspects of paediatric dentistry revealed that $84 \%(n=589)$ of the respondents never used preformed stainless steel crowns in the restoration of a deciduous molar; with a further $12 \%(n=87)$ indicating that they used such crowns occasionally. Regarding the most commonly used materials for the restoration of Class II cavities in deciduous molars, GICs were selected by 55\% $(n=386)$ of the respondents, with compomers and resin-modified GICs being selected by a further $28 \%$ $(n=198)$ of the respondents. Dental amalgam was selected by only $14 \%(n=96)$ of the respondents.

\section{DISCUSSION}

As acknowledged in another of this series of three papers, ${ }^{1}$ the data obtained relates to practitioners and their practices in the North West of England and Scotland and, as such, cannot be considered to apply to practitioners and dental practices throughout the UK. However, about 1 in 25 general dental practitioners in the UK participated in the study and, as a consequence, the findings are considered to provide a useful, and possibly to many, somewhat surprising insight into aspects of the everyday clinical practice of dentistry in the UK. It is also acknowledged that surveys of the type reported suffer a number of limitations. It is considered, however, that strenuous efforts were made to minimise such limitations in the present study.

The 70\% response rate to the 79-question questionnaire, including many questions tried and tested in annual surveys of dentists in the USA, may be considered to say something about the 
respondents' perception of the relevance of the questions posed to them. Understanding dentistry as it is practised in the 'real world' of everyday general dental practice is important in, for example, planning continuing education programmes and setting priorities for research in primary dental care. The present study is but a snapshot of everyday dentistry at the time of the survey. Regular surveys of the type reported, possibly on an annual basis, as conducted by CRA in the USA, would provide invaluable data on trends in clinical practice in the UK.

\section{Dental amalgam}

Dental amalgam may remain the most commonly used restorative material for one of the commonest operative procedures in the everyday practice of dentistry in the UK - the restoration of a Class II cavity. However, the finding in the present study that only $60 \%$ of respondents agreed that amalgam should continue to be used with a further $30 \%$ of respondents being uncertain on this issue, may be considered to give an indication of a dramatic future change in the provision of direct restorations in the UK. Factors delaying a reduction in the use of dental amalgam may range from general dental services fees and regulations, through worries about the limitations of alternative materials, to a lack of confidence and expertise in placing state-of-the-art composite restorative systems in Class II cavities.

In moving towards ever-increasing, patient-centred care, it is suggested that there is already a very considerable tension between patients' wishes and expectations of tooth-coloured restorations and practitioners' confidence and expertise in the use of, in particular, resin-based composites in the restoration of posterior teeth. How is this dilemma to be resolved when new composite systems and techniques continue to be introduced faster than the evidence necessary to convince patients and practitioners (ie the results of long-term clinical trials) can be amassed? This is not a new problem. ${ }^{6}$ Many researchers around the world are believed to have tried without success to secure research funding to answer such questions. There are, however, the competing priorities of new science and how it may transform healthcare in general. So, where does that leave us? Further research is undoubtedly necessary and it should be largely practice-based. The issue, it is suggested, centres on the funds to conduct the research. What other worldwide billion-dollar business, ${ }^{3}$ let alone multi-million-dollar national activity attracts so little funding for the research and development of future service provision?

\section{Glass-ionomer cements}

The findings of the present study in relation to the use of GICs are of considerable interest in that only 54\% of the respondents indicated that they used such materials as a restorative. Practitioners in the North West of England were less likely to use GICs as direct restorations when compared with practitioners in Scotland. In contrast, younger practitioners seem to use GICs for restorations more than older practitioners. It was also noted that less than half of the respondents found applications for GICs as liners and bases. The latter finding may be related to what is believed to be a widespread practice of total etching techniques, ${ }^{7}$ and given limited post-operative difficulties with total etching, a greatly reduced use of liners and bases under direct restorations in general. It was interesting to note that younger practitioners were more likely to use GICs as bases. Only time will tell what effects, if any, this variation in operative technique will have on the incidence of endodontic problems in practice.

As with many aspects of the findings of the present study, it would have been most helpful to include a number of follow-up questions such as: reasons for not using GICs as restoration materials, especially given the regional variation in use. In the absence of answers to such questions any attempt to explain the findings would be conjecture. It is worth remembering that the questionnaire included 18 sections and a total of 79 questions and the purpose of the survey was to provide a profile of everyday aspects of contemporary general dental practice. The frustration in not being able to answer all the readers' questions is a measure of the need for further research of the type reported.

\section{Bleaching}

It was not considered surprising, even at the time of this survey when there was great controversy about bleaching and bleaching products, that somewhere between 35\% and 52\% of the respondents provided bleaching treatments. Patient pressure to have their teeth bleached has been very considerable and growing in recent years; the growth in this aspect of clinical practice having been fuelled by substantial media interest in 'tooth whitening' and its purported 'rejuvenating effects'.

In contrast, it was possibly somewhat surprising that soft tissue inflammation and tooth sensitivity had been experienced as side effects by such a large proportion of those providing bleaching (Table 1). It is acknowledged that the findings presented do not give insight into the incidence of such side effects, but nevertheless they are findings which, it is suggested, should be viewed as justification for further investigation. The figure obtained for tooth sensitivity with home-based bleaching $(72 \%$ of bleaching providers) is suggested to be of particular note and possibly cause for some concerns, although existing literature indicates that such sensitivity is typically a short-term phenomenon and, if it does not resolve spontaneously, can usually be treated by relatively simple means. ${ }^{8}$ The issue may simply be one of overzealous home bleaching; contrary to the advice of the practitioner. Reassuringly, bleaching, whether home-based or practice-based, was not found to give rise to systemic or other side effects to any appreciable extent.

\section{Endodontics}

Given the many, varied significant advances in endodontics in recent times, the widespread practice of endodontics around the world and numerous reports of high success rates, it was considered a matter of concern that only $75 \%$ of the respondents considered root canal therapy to be safe, with 15\% of the respondents indicating that they were beginning to question the acceptability of standard root canal procedures. Could such findings be linked to $61 \%$ of the respondents indicating that they did not use rubber dam and the apparent widespread reliance on cold lateral condensation techniques, especially by younger practitioners, or are other factors, such as NHS fees for endodontic procedures, behind this finding? Whatever the reason, it is certainly cause for concern if, as it would appear from the findings, a sizeable minority of general dental practitioners may be found to consider endodontics as currently practised to be unsafe.

\section{Rubber dam}

It was of note that practitioners in Scotland tended to use rubber dam more frequently for endodontic procedures. Why this might be is unclear. It is suggested that further research is needed to investigate such matters, let alone determine if routine use of rubber dam affects treatment outcomes.

\section{Paediatric dentistry}

Finally, in relation to paediatric dentistry, the findings - certainly those in relation to the use of stainless steel crowns, ${ }^{9}$ would appear to be contrary to evidence-based practice. Concerning the findings in relation to the materials selected for the restoration of Class II cavities in deciduous molar teeth, one is certainly left wondering what qualities GICs and related materials have to 
make them the materials of choice for one of the commonest operative procedures in paediatric dentistry when, at one and the same time, only $54 \%$ of the same practitioners would use GICs as a restorative in permanent teeth. Is it something to do with the longevity of restorations of GICs in everyday clinical practice; are issues of patient acceptability important in understanding such matters or are the challenges of treating children with caries such that the ease of use of GICs is the overriding factor in materials selection? Practice-base researched answers to such questions would be most helpful.

A further general point, raised by findings of the type reported in the present paper, is the apparent gulf which exists between what is considered to be evidence-based and, as a consequence, typically taught in dental schools and what is practised in the 'real world'. Is it any wonder that new graduates continue to find it challenging to make the transition from undergraduate dental student and vocational dental practitioner, let alone an independent practitioner? Are third party rules and regulations for remuneration a barrier to evidence-based practice? Do evidence-based methodologies rely too heavily on the outcome of research conducted in environments other than general dental practice, where most people are treated? How can we close the gulf? These are but some of the questions arising from the present work which, it is suggested, need to be answered in the interests of patient protection and the provision of best quality dental care.

\section{CONCLUDING REMARKS}

In providing insight into the provision of direct restorations in the 'real world' of general dental practice in the North West of England and Scotland, this report may be considered to pose more questions than provide answers to everyday issues in general practice. It is suggested that this is a positive outcome, as it brings to the fore challenges for the future. Together with the other two papers in the current series, the reporting of the present survey will hopefully act as a potent stimulus for the further development and funding of practice-based research in UK dentistry.

1. Burke FJ T, Wilson N H F, Christensen G J, Cheung SW, Brunton P A. Contemporary dental practice in the UK: demographic data and practising arrangements. Br Dent 2005; 198: in press.

2. Brunton PA, Christensen G J, Cheung S W, Burke F J T, Wilson N H F. Contemporary dental practice in the UK: Indirect restorations and fixed prosthodontics. BrDent J 2005; 198: in press.

3. Mjör I A. Repair versus replacement of failed restorations. Int Dent J 1993; 43: 466472.

4. Jokstad A, Bayne S, Blunck U, Tyas M, and Wilson N. Quality of dental restorations. FDI Commission Project 2-95. Int Dent J 2001; 51: 117-158.

5. Annual Digests of Statistics (2000-2002). Eastbourne: Dental Practice Board.

6. Wilson N H F. Evaluating materials: relationships between laboratory investigations and clinical studies. Oper Dent 1990; 15: 149-155.

7. Burke FJ T, McHugh S, Hall A S, Randall R C, Widstrom E, Forss H. Amalgam and composite used in UK general dental practice in 2001. Br Dent J 2003; 194: 613-618.

8. Greenwall L. Bleaching techniques in restorative dentistry. London: Martin Dunitz, 2001.

9. Randall R C, Vrijhoef M M A, Wilson N H F. Efficacy of preformed metal crowns vs. amalgam restorations in primary molars: A systematic review. J Am Dent Assoc 2000; 131:337-343 